McDaniel, S. H., Belar, C. D., Schroeder, C., Hargrove, D.S., \& Freeman, E. L., (2002). A training curriculum for professional psychologists in primary care. Professional Psychology: Research and Practice, 33(1): 65-72 (Feb 2002). Published by the American Psychological Association (ISSN: 0735-7028). This article may not exactly replicate the final version published in the APA journal. It is not the copy of record.

\title{
A Training Curriculum for Professional Psychologists in Primary Care
}

Susan H. McDaniel, Cynthia D. Belar, Carolyn Schroeder, David Scott Hargrove, and Esther Lerman Freeman

\begin{abstract}
Primary care psychology is a growing field that requires specific training opportunities for successful practice. The knowledge and skills that practitioners need for work in this setting are outlined here in detail. This curriculum integrates literature and experience in family psychology, health psychology, and pediatric psychology; considers multiple levels of education and training; and provides illustrative examples. It is a first attempt in an evolving process of integrating historical and cutting edge literature from many areas of psychology and other disciplines to contribute to comprehensive primary care psychology training. It can be used by programs and individual practitioners alike in designing education and training experiences.
\end{abstract}


What knowledge and skills do psychologists need to work in primary care? As the need for psychology to become an integral part of primary health care has become increasingly clear, a literature has developed that describes professional role functioning in primary care settings. This article addresses the knowledge and skills required and proposes a curriculum that can be used as a starting point by programs and individual practitioners in the design of education and training experiences in primary care psychology. The curriculum is followed by a discussion of its application at different levels of education and training along with examples of current education and training programs in primary care psychology. We end with thoughts about future directions for education and training in primary care psychology.

\section{BACKGROUND}

By definition, primary care is the most likely port of first call when a person decides that a health problem exists. Often that problem is an undifferentiated bundle of biological and psychosocial issues that present as symptoms to a primary care physician or nurse. Primary care professionals must also provide coordinated, comprehensive, biopsychosocial care that is continuous over time (Institute of Medicine, 1996). These characteristics of primary care make it an important arena for psychologists to work as part of the health care team.

Primary care professionals are charged with the initial assessment and treatment of a wide range of human difficulties. This is a generalist mode of practice that must be responsive to a wide range of physical and psychological problems. In many cases, the difficulties for which assistance is sought are successfully treated in the primary care setting. In others, one must refer to specialists for both diagnosis and treatment. Because most, if not all, health problems have behavioral components, a biopsychosocial approach to primary care requires sensitivity and skill.

Appropriately trained psychologists can provide important consultation to physicians and nurses and contribute to the assessment and treatment of problems seen in primary care. It is well documented that patients with mental disorders make up a large proportion of all primary care patients, about 20-25\% (Spitzer et al., 1995); of these, over half are treated only in primary care (Schurman, Kramer, \& Mitchell, 1985). However, less than half of these mental health disorders are detected by health care professionals (Badger et al., 1994). This failure may result in the delivery of substandard or inappropriate care. It may also influence the cost of services because primary care patients with mental disorders use more medical services and have increased disability, illness, and mortality than do other patients (Druss, Rohrbaugh, \& Rosenheck, 1999; Olfson et al., 1997). For example, in the 6 months after a 
heart attack, patients with depression are twice as likely to die as those with the same severity of disease who are not depressed. In fact, depression is a greater risk factor for mortality than any biological factor following a heart attack (Frasure-Smith, Lesperance, \& Talajic, 1993).

In addition to services for mental health problems in primary care, professional psychologists also provide services that affect health status through pathways other than mental health (e.g., management of pain, adherence to medical regimens, development of healthy habits, management of stressful medical procedures, psychophysiology). In fact, Belar (1996) argued that all medical visits should be considered psychological in nature, asserting that $100 \%$ of visits have behavioral components.

Psychologists who wish to participate in the primary care workforce must be educated and trained to work in this context. Despite this need, few graduate programs and few internships or fellowships are available that focus on primary care psychology. Yet more could be done within existing programs to integrate current knowledge and skills with specific activities in primary care and to provide opportunities for the interprofessional collaboration that is fundamental to primary care practice.

Drawing on work in family, health, and pediatric psychology (see, for example, Belar \& Deardorff, 1995; Drotar, 1995; McDaniel, Hepworth, \& Doherty, 1992), we propose an integrated curriculum for training professional psychologists. Systems theory provides an overall understanding of the problem, the patient, the family and social context, and the health care delivery system. Family, health, and pediatric psychology add to a toolbox of assessment and intervention techniques, as well as providing relevant research that informs an integrated practice.

The resources for the development of this curriculum were (a) published literature relevant to primary care psychology; (b) relevant American Psychological Association (APA) task force reports (e.g., Interprofessional Health Care Services in Primary Care Settings: Implications for the Education and Training of Psychologist; APA, 1998; Primary Care Task Force Final Report; APA CAPP Primary Task Force, 1996); (c) the perspectives of the authors and consulting reviewers; (d) data on the most common presenting conditions in ambulatory care (National Ambulatory Medical Care Survey: 1997 Summary; Woodwell, 1999); and (e) data concerning the leading causes of morbidity and mortality that can be prevented or reduced through behavioral interventions (U.S. Department of Health and Human Services, 1999).

The curriculum is based on seven assumptions, distilled from the literature as cited above: (a) Primary care psychologists function as generalists who play multiple roles on the primary health care team; (b) the education and training of psychologists must be 
developmental, biopsychosocial, and systemic in nature; (c) primary care includes a focus on prevention and wellness; (d) primary care is collaborative in nature; (e) primary care attends to the various interpersonal relationships that characterize its context; $(f)$ primary care psychologists bring to the health care team expertise in behavioral health, developmental psychology, psychopathology, family and systems issues, and research skills; and (g) primary care is practiced in many different settings. The curriculum is presented in outline form, but an expanded version with more extensive resource information and recommended exercises is found in McDaniel, Hargrove, Belar, Schroeder, and Freeman (in press).

\section{A CURRICULUM FOR THE EDUCATION AND TRAINING OF PRIMARY CARE PSYCHOLOGISTS}

A psychologist who works in primary care is a general practitioner who has skills in the psychological assessment and intervention of common health problems experienced by patients and families throughout the lifespan. The primary care psychologist works collaboratively with other health care professionals to provide continuity of care using a biopsychosocial model. Thus, the curriculum for education and training of generalist psychologists is distinguished by its breadth and comprehensiveness, its provision of opportunities to work with health care professionals other than those in the mental health field, and its explicit attention to experiences involving continuity of care within a systems perspective.

The curriculum proposed is intended to supplement general core training in the discipline of psychology as specified by the Guidelines and Principles for Accreditation of Programs in Professional Psychology (APA, 2000). Within professional psychology, it represents a merging of knowledge, skills, and attitudes fundamental to clinical, counseling, school, family, clinical child, pediatric, and clinical health psychology as relevant for primary care psychology.

Effective training of psychologists for work in primary care settings takes place within a biopsychosocial context (Engel, 1977). This model emphasizes the reciprocal and dynamic influence of biological, psychological, and social forces on etiology, experience of illness, and treatment of disease. Whereas the interaction among components is integral to the experience of illness, in training the component parts must be identified and clearly articulated. The core areas of knowledge and skills for primary care psychology are listed in Table 1. (See Appendix A for the specific training objectives associated with each core area; see Appendix B for common conditions seen in primary care.) 


\section{MODELS OF EDUCATION AND TRAINING IN PRIMARY CARE PSYCHOLOGY}

Multiple levels of education and training must be addressed as the profession of psychology moves toward increased participation in primary care. At one level, students can prepare for practice in primary care as part of their initial preparation for careers as professional psychologists. Optimally, this education begins at the undergraduate level, as students entering the field obtain backgrounds not only in psychology but in biology and sociology as well. Graduate programs then provide additional coursework and practica in primary care settings. Other students may become primary care psychologists through education and training at the internship and postdoctoral levels. Yet another pathway to competence in primary care can be pursued by psychologists who are already certified for independent practice yet seek to expand their scope of practice through systematic continuing education and training. All levels of education and training need to offer experiences that train not only for competence (i.e., the development of knowledge and skills) but also for capability (i.e., the ability to adapt to change, generate new knowledge, and continuously improve performance). This is accomplished through multiple modes of learning, including experiential learning, shadowing, mentoring, small-group learning, role play, teambuilding exercises, and so forth, in addition to more formal, didactic learning (Fraser \& Greenhalgh, 2001).

Contexts in which interdisciplinary health care teams are valued offer the greatest opportunity for training primary care psychology (McDaniel \& Campbell, 1997). Medical schools and community-based residency programs that involve psychologists provide opportunities for both formal internships or postdoctoral training and supervised practica in primary care psychology. Given the recent focus on generalist versus specialist medicine, the primary health care medical specialties of family practice, pediatrics, and general internal medicine offer the greatest opportunities for primary care psychology. For example, the accreditation standards for family medicine residency programs require at least one behavioral scientist to be on the faculty (Accreditation Council of Graduate Medical Education, 1997); thus, many of these programs already have licensed psychologists in-house who could participate in training. These opportunities dovetail with the increased emphasis on health in clinical, counseling, and school psychology and can make them ripe for creative partnerships.

Illustrations of successful primary care psychology training emphasize the skills needed by the generalist psychologist, including skills in interdisciplinary collaboration. First, psychologists-in-training need to gain the skills that solidify their identity as psychologists (Hargrove, 1982). Psychologists who have a positive 
professional identity are most likely to be able to work in collaborative primary care settings.

\title{
Table 1
}

Core Areas of Knowledge and Skills For

Primary Care Psychology

\author{
1. Biological components of health and illness \\ 2. Cognitive components of health and illness \\ 3. Behavioral and developmental aspects of health and illness \\ 4. Sociocultural components of health and illness \\ 5 . Health policy and health care systems \\ 6. Common primary care problems \\ 7. Clinical assessment of common primary care conditions \\ 8. Clinical interventions in primary care \\ 9. Interprofessional collaboration in primary care \\ 10. Ethical issues in primary care \\ 11. Legal issues in primary care \\ 12. Professional issues in primary care
}

Although some graduate psychology programs may have difficulty developing opportunities in primary care settings, student experience in any interdisciplinary team setting is useful preparation for later training in primary care. An example of such an experience is the linkage relationship between the University of Mississippi Department of Psychology and the North Mississippi Regional Center in Oxford. Psychology trainees are assigned to work in interdisciplinary teams that are composed of physicians, nurses, occupational therapists, social workers, audiologists, and others specific to the function of a particular unit of the center. The students quickly realize the importance of understanding the perspective of other disciplines and professions and being able to communicate with them. Wright State School of Professional Psychology has long had a focus on training clinical psychology doctoral students to work on interdisciplinary teams. As part of their overall program that includes practicum placements in primary care, their faculty coteach (with physician and nursing faculty) a graduate seminar on interprofessional practice for medical, nursing, and psychology students (Talen, Graham, \& Walbroehl, 1994).

Direct training in primary care, which emphasizes both generalist and collaborative skills, is found in the Department of Clinical and Health Psychology at the University of Florida. This program is housed in an academic health science center along with colleges such as nursing, medicine, dentistry, and pharmacy. The department offers an APA-accredited clinical psychology program, internship program, and selected postdoctoral training fellowships. The associated Shands Teaching Hospital is a major center for research and tertiary care, and it provides onsite clinical training 
opportunities. In addition, the department collaborates in several off-site efforts that are fundamental to its primary care training, including the Community Health Center at Eastside (a University of Florida outreach to an underserved Gainesville community with a significant minority population) and the Rural Psychology Program, which serves three rural countries (Sears, Evans, \& Perry, 1998).

Training in pediatric primary care psychology in a private community-based primary care clinic is described by Schroeder (1997b). This clinic is located in a small university town with a major university and medical school (University of North Carolina). The pediatricians have clinical appointments at the university, and the psychologists doing the training are on the university faculty or have clinical appointments in the medical school. Graduate students, interns, and postdoctoral psychology fellows have the opportunity to participate in a wide spectrum of clinical assessment, treatment, prevention, and research activities with health care professionals practicing in the setting.

A model for training in primary care psychology at the internship level has been developed in the Veterans' Administration (VA) system. The disciplines include psychology, medicine, pharmacy, nursing, and nutrition. In the program, which was constructed explicitly as an interdisciplinary training model called PRIME, interns provide assessment (e.g., for depression, anxiety, and other psychopathology; neuropsychological screens), intervention (e.g., individual, family, and group therapy for patents with somatization; overutilization of medical services; non-adherence to treatment plans; problems coping with chronic illness; women's health problems; health behavior problems), and referral services for mental and behavioral health issues of the patients assigned to their teams (e.g., psychiatric treatment, addiction treatment). PRIME interns also complete a program evaluation or applied research project (Zilberg \& Carmody, 1995). Some VA hospitals have maintained aspects of the program; the VA remains an innovative environment for the delivery and training of multidisciplinary primary care services.

Another innovative training model was described by James and Folen (1999). At Tripler Army Medical Center in Hawaii, health psychologists serve as primary care case managers on both an inpatient and an outpatient basis. (Psychologists independently admit and discharge patients.) Interns and postdoctoral fellows attend classes with family practice physicians, oral surgery residents, and nurse practitioners to learn history taking, physical examination, laboratory tests and interpretation, and case management. Advanced training includes pathophysiology, health psychology, and brief neuropsychological examinations, among other topics. Inpatient training focuses on the management of patients with essential hypertension, Type 2 diabetes, obesity, and hypercholesterolemia. 
The military has a long history of training nonphysician providers to manage patient care; thus, psychologists as primary care managers may have very rich opportunities to develop expanded roles and functions in military health care.

A model for training primary care psychologists at the postdoctoral level is exemplified by the fellowship program at the University of Rochester Medical School's program in primary care family psychology. The 1-2 year fellowship includes family therapy seminars, live supervision in multidisciplinary teams, and clinical placement in primary care settings along with family medicine, reproductive health, geriatric, internal medicine, and pediatric residents and faculty, as well as students and staff from nursing, social work, and nutrition. Students also attend interdisciplinary seminars on professional writing, family systems medicine, and personal awareness. They participate in interdisciplinary interviewing rounds and teach psychosocial seminars to medical residents. The development of collaborative interdisciplinary relationships and collaborative treatment plans with patients and families is a major focus of these fellowships.1

\section{CONTINUING PROFESSIONAL EDUCATION AND EXPANSION OF PRACTICE}

Workshops related to primary care psychology occur regularly through the Office of Continuing Professional Education of the APA as well as through state and local psychological association meetings. An intensive professional development opportunity is provided by the University of Rochester's weeklong, interdisciplinary Medical Family Therapy Institute. This program combines lectures on a variety of primary-care-relevant topics (e.g., bereavement, collaborative pediatric practice, infertility, pseudoseizures, somatization, spirituality, and illness) by an interdisciplinary faculty committed to collaborative, integrated care. The course is followed by a distance education sequence in which participants take a reading course and write reaction papers, communicate by e-mail, and have group consultation once per month by phone. 2 The practicing psychologist can use these workshops to build on already developed professional skills to expand into primary care psychology.

In general, the issues for practicing generalist psychologists to begin working in primary care are twofold. First, they need to assess the skills they possess that could most readily translate into primary care (e.g., weight loss interventions, anxiety management, couples counseling). Equally important is learning about the environment and culture of a primary health care practice (McDaniel \& Campbell, 1986; McDaniel et al., 1992; Strohsahl, 1996). Although opportunities for this learning are provided for students, interns, and fellows in structured programs, the independent practitioner 
will have to be creative and courageous in finding and developing these opportunities. (For additional ideas, see McDaniel et al., in press, and the APA Education Directorate website.) The self-assessment model developed for ethical expansion of practice in clinical health psychology might be easily adapted for use in primary care psychology as well (Belar et al., 2001).

Some areas are natural points for departure for individual psychologists. For example, a child psychologist might begin by offering services that he or she already provides by donating several hours per week to a local hospital pediatric clinic. The psychologist then has the opportunity to demonstrate to the pediatrician the contributions he or she can make to the care of patients while learning more about the practice of pediatrics. The psychologist will be learning by experience and have the opportunity to assess what needs to be learned to be more effective in this arena. Likewise, a psychologist specializing in women's issues might try a similar arrangement in an obstetrics-gynecology practice, as might a geropsychologist in an internist's office.

Finding a supervisor or mentor from whom to learn new skills is something familiar to all psychologists. At this time, there is no one organization or resource that lists all primary care psychologists. However, relevant APA divisions (Family, Health, Independent Practice, or Pediatric Psychology) can identify someone willing to provide consultation. A department of psychiatry, behavioral medicine, pediatrics, or family medicine at a local medical school might also be helpful in finding a primary care psychologist mentor.

Independent practitioners can also become educated about particular diseases and the effects they have on patients' lifestyles, emotions, physical function, and sexuality through reading. (See the resources listed in McDaniel et al., in press, or the APA Education Directorate website.) Medline and PsycINFO searches can provide up-to-date review articles.

\section{FUTURE DIRECTIONS IN PRIMARY CARE PSYCHOLOGY}

Achieving psychology's potential to contribute to primary care services for the public depends on the development of well-trained professionals. Thus far we have focused on the knowledge, skills, and attitudes relevant for the individual psychologist. In considering future directions, we also note issues that must be addressed so that education and training in primary care psychology will be more readily available. 


\section{The Need for More Faculty Role Models}

There are a limited number of faculty who have direct experience in primary care psychology, and there are no precise data on the availability of primary care psychologists in the health care workforce. We have noted some programs in which training is available, but training is insufficient given the number of doctorates being awarded in professional psychology each year. Thus, the field needs easily accessible, organized, and sequential professional development programs to help develop this expertise in faculty, who can then serve as appropriate role models. In the absence of relevant, supervised training, expansion of practice into primary care could be fraught with difficulties and could even damage the credibility of the profession.

\section{The Need for More Broad Interdisciplinary Experiences}

When interdisciplinary experience occurs in professional psychology, it is often with other mental health professions. This is insufficient for primary care psychology. Students must have experience with at least the medical and nursing professions and ideally with trainees, faculty, and practitioners in many health professions. Courses in health care ethics and health care policy are especially well suited to interdisciplinary student groupings. It is also important to note that training in a health care setting itself is insufficient, as parallel work without collaboration can occur despite the multidisciplinary nature of the institution. Academic administrators and funding agencies must ensure that interdisciplinary training occurs.

\section{The Need for Organizational Collaboration}

For psychology to contribute maximally to primary care requires continuing collaboration between psychology specialities, such as clinical, family, health, and pediatric psychology. It is also essential for the APA to continue collaborations and find new joint ventures with primary care organizations, such as the American Association of Family Practice, the Society for General Internal Medicine, the Ambulatory Pediatric Association, and the American Association of Family Nurse Practitioners. The opportunity for APA to participate in the Bureau of Health Affairs Primary Care Policy Fellowship also facilitates interorganizational collaborations. 
The Need for Increased Funds to Treat Mental Health Problems in Primary Care

Because the majority of mental health problems are treated in primary care settings, increased federal funds should be directed toward training psychologists to work collaboratively in these settings. Federal agencies that support mental health education and research need to facilitate the development of both research and clinical expertise in primary care psychology.

\section{The Need to Communicate the Unique Role of Psychology in Primary Care}

In close collaboration with other disciplines, professionals may begin to question the unique contribution of their discipline. Among behavioral health professionals, PhD psychologists bring systematic research training and advanced clinical training; they often become the program developers and evaluators and clinical innovators in their settings. Many primary care psychologists rise to administrative and other positions of leadership and become valued consultants to other leaders because of their understanding of systems, relationships, and behavior.

\section{SUMMARY}

The primary care psychologist has much to offer the comprehensive delivery of primary care as evaluator, educator, program developer, patient consultant, team consultant, researcher, administrator, and therapist. Psychologists have the opportunity to collaborate in the development of innovative programs to treat patients who otherwise would not receive specialized mental or behavioral health care. The primary care setting offers psychologists the opportunity to help this diverse array of patients and other professionals in the promotion of health and the relief of suffering.

\section{NOTES}

1. For more information, see the fellowship Web site at www.rochester. edu/smd/psych/education/psychology/postdoc/index/htm

2. For more information, see the institute Web site at www.urmc.rochester.edu/smd/psych/clinical/Family_Marriage/med_fam_therapy_inst.htm 


\section{REFERENCES}

Accreditation Council of Graduate Medical Education. (1997). Program requirements for residency education in family practice. Chicago:

Author.

American Psychological Association, Committee for the Advancement of Professional Psychology (CAPP) Primary Care Task Force. (1996).

Primary Care Task Force final report. Washington, DC: Author.

American Psychological Association (APA). (1998). Interprofessional health care services in primary care settings: Implications for professional education and training of psychologists (SAMHSA/HRSA Project on Managed Behavioral Health Care and Primary Care; SAMHSA Work Order No. 97M220464). Washington, DC: Author.

American Psychological Association (APA). (2000). Guidelines and principles for accreditation of programs in professional psychology. Washington, DC: Author.

Badger, L. W., deGruy, F., Hartman, J., Plant, M. A., Leeper, J., Anderson, R., et al. (1994). Patient presentation, interview content and the detection of depression by primary care physicians. Psychosomatic Medicine, 56, 128-135.

Belar, C. D. (1996). A proposal for an expanded view of health and psychology: The integration of behavior and health. In R. J. Resnick \& R. H. Rozensky (Eds.), Health psychology through the lifespan (pp. 77-81). Washington, DC: American Psychological Association.

Belar, C., Brown, R., Hersch, L., Hornyak, L., Rozensky, R., Sheridan, E., et al. (2001). Self-assessment in clinical health psychology: A model for the ethical expansion of practice. Professional Psychology: Research and Practice, 32, 135-141.

Belar, C. D., \& Deardorff, W. W. (1995). Clinical health psychology in medical settings: A practitioner's guidebook. Washington, DC: American Psychological Association.

Drotar, D. (1995). Consulting with pediatricians: Psychological perspectives. New York: Plenum Press.

Druss, B. G., Rohrbaugh, R. M., \& Rosenheck, R. A. (1999). Depressive symptoms and health costs in older medical patients. American Journal of Psychiatry, 156, 477-479.

Engel, E. (1977, April 8). The need for a new medical model: A challenge for biomedicine. Science, 196, 129-136.

Fraser, S. W., \& Greenhalgh, T. (2001). Coping with complexity: Educating for capability. British Medical Journal, 323, 799-803. 
Frasure-Smith, N., Lesperance, F., \& Talajic, M. (1993). Depression following myocardial infarction: Impact on 6-month survival. JAMA, 270, 1819-1825.

Hargrove, D. S. (1982). The rural psychologist as generalist: A challenge for professional identity. Professional Psychology: Research and Practice, 13, 302-308.

Institute of Medicine. (1996). Primary care: America's health in a new era. Washington, DC: National Academy Press.

James, L. C., \& Folen, R. A. (1999). A paradigm shift in the scope of practice for health psychologists: Training health psychologists to be primary care case managers. Professional Psychology: Research and Practice, 30, 352-356.

McDaniel, S. H. \& Campbell, T. L. (1997). Training health professionals to collaborate. Family Systems \& Health, 15, 353-359.

McDaniel, S. H., Hargrove, D. S., Belar, C., Schroeder, C., \& Freeman, E. (in press). A training curriculum for professional psychologists in primary care. In R. Frank, S. McDaniel, J. Bray, \& M. Heldring (Eds.),

Primary care psychology. Washington, DC: American Psychological Association.

McDaniel, S. H., Hepworth, J., \& Doherty, W. (1992). Medical family therapy: A biopsychosocial approach to families with health problems. New York: Basic Books.

Olfson, M., Fireman, B., Weissman, M. M., Leon, A. C., Sheehan, D. V., Kathol, R. G., et al. (1997). Mental disorders and disability among patients in a primary care group practice. American Journal of Psychiatry, 154, 1734-1740.

Schroeder, C. (1997a). The changing practice paradigm in pediatric settings. In R. J. Illback, C. Cobb, \& H. Joseph (Eds.), Integrated services for children and families: Opportunities for psychological practice (pp. 109-131). Washington, DC: American Psychological Association.

Schroeder, C. (1997b). Conducting an integrated practice in a pediatric setting. In R. J. Illback, C. Cobb, \& H. Joseph (Eds), Integrated services for children and families: Opportunities for psychological practice (pp. 221-255). Washington, DC: American Psychological Association.

Schurman, R. A., Kramer, P. D., \& Mitchell, J. B. (1985). The hidden mental health network: Treatment of mental illness by nonpsychiatrist physicians. Archives of General Psychiatry, 42, 89-94.

Sears, S. F., Evans, G. D., \& Perry, N. W. (1998). Innovations in training: The University of Florida Rural Psychology Program. Professional Psychology: Research and Practice, 29, 504-507. 
Spitzer, R. L., Kroenke, K., Linzer, M., Hahn, S. R., Williams, J. B., deGruy, F. V., et al. (1995). Health-related quality of life in primary care patients with mental disorders: Results from the PRIME-MD 1000 study. JAMA, 274, 1511-1517.

Strohsahl, K. (1996). Confessions of a behavior therapist in primary care: The odyssey and the ecstasy. Cognitive and Behavioral Practice, 3, 1-28.

Talen, M. R., Graham, M. C., \& Walbroehl, G. (1994). Introducing multiprofessional team concepts and practices into the curriculum: A challenge for health care educators. Family Systems Medicine, 12, 354360.

U.S. Department of Health and Human Services. (1999). Mental health: A report of the Surgeon General's Executive Summary. Rockville, MD: US Department of Health and Human Services; Substance Abuse and Mental Health Services Administration, Center for Mental Health Services, National Institutes of Health, National Institute of Mental Health.

VandenBos, G., DeLeon, P. H., \& Belar, C. (1991). How many psychologists are needed? It's too early to know. Professional Psychology:

Research and Practice 22, 4410-4448.

Weiss, B. (2000). 20 common problems in primary care. New York: McGraw-Hill.

Woodwell, D. A. (1999). National ambulatory medical care survey: 1997 summary. Hyattsville, MD: U.S. Department of Health and Human Services.

Zilberg, N. J., \& Carmody, T. P. (1995). New directions for the education of clinical psychologists: The primary care setting, the VA's PRIME program, and the in-depth generalist model. Journal of Clinical Psychology in Medical Settings, 2, 109-127. 


\section{Appendix A}

\section{Core Knowledge and Skills for Primary Care Psychology}

\section{Biological Components of Health and Illness}

Objective: To understand the biological components of health, illness, and disease and the interaction between biology and behavior, including

a. general knowledge of human anatomy, physiology, and pathophysiology

b. general knowledge of pharmacology, with a special focus on those medications with known effects on behavior

\section{Cognitive Components of Health and Illness}

Objective: To understand how leaming, memory, perception, and cognition can influence health and health behavior, including

a. knowledge of health belief models of patients and their families and how these beliefs influence identification of health problems and adherence to treatment regimens

b. knowledge of beliefs and attitudes that mediate help seeking

c. knowledge of cognitive factors that influence reactions to initial diagnoses and the processing of health information

\section{Affective Components of Health and Illness}

Objective: To understand how emotions and motivation can influence health and health behavior, including

a. knowledge of how affect influences cognition and attitudes that mediate help-seeking

b. knowledge of affective factors that influence reactions to initial diagnoses and the processing of health information

c. knowledge of affective reactions to illness, injury, and disability

d. knowledge of medical problems that can present as affective disorders (e.g., thyroid disorders, reactions to steroid medication)

4. Behavioral and Developmental Aspects of Health and Illness

Objective: To understand behavioral aspects of health, help-seeking behavior, response to illness and treatment, and prevention, as well as how development and individual differences may interact with cognitive, affective, and behavioral components, including:

\section{Continues}


a. knowledge of behavioral risk factors for problems seen in primary care

b. knowledge of relationships among coping styles and health

c. knowledge of the relationships among age, developmental context, and health

d. knowledge of the impact of psychopathology on response to illness and recovery

e. knowledge of how operant and classical conditioning affect health and health behavior

\section{Sociocultural Components of Health and Illness}

Objective: To understand social and cultural factors in the development of health problems, access to health care, help-seeking behavior, adherence to medical regimens, and prevention, including

a. knowledge of the impact of interpersonal relationships on health and health behavior, and awareness of

(1) partner and family influences,

(2) the impact of health professional(s), patient, and family communication on health,

(3) the positive and negative effects of the social network and health

b. knowledge of relationships among disease management and ethnicity, race, class, culture, and health behavior

c. knowledge of socioeconomic factors in health status and health care, including

(1) knowledge of the relationship between socioeconomic status and health

(2) knowledge of socioeconomic and sociopolitical factors specific to a local community with respect to practice and resources

d. knowledge of relationships between religion and health

e. knowledge of issues related to sexual orientation and health

f. knowledge of issues related to disability and health

g. knowledge of issues related to gender and health

h. knowledge of health care consumer groups and their impact on health policy and health care delivery

\section{Health Policy and Health Care Systems}

Objective: To understand how health policy and health care systems affect health, including

a. awareness of impact of health policy on health and health care, including

(1) knowledge of health care financing

(2) awareness of behavioral health carveouts as impediments to integrated primary care

(3) knowledge of the underinsured and uninsured in terms of their health care needs and community strategies to care for them

(4) knowledge of trends in health policy

b. knowledge of specific characteristics and sociopolitical features of the health care system, including

(1) awareness of health care system design

(2) awareness of impact of mind-body dualism on design of health care services

c. knowledge of specific characteristics and sociopolitical features of primary care, including awareness of

(1) the role of primary care in the current health care system

(2) similarities and differences between primary and specialty care, and how referrals and communications between them generally occur

(3) similarities and differences in various primary care settings (family practice, obstetrics-gynecology, pediatrics, general internal medicine, geriatrics)

\section{Common Primary Care Problems}

Objective: To acquire knowledge concerning the biological, cognitive, affective, behavioral, and interpersonal aspects of the most common con- ditions and issues seen in primary care (see Appendix B), with a specific focus on the following as relevant:

a. etiology

b. signs and symptoms

c. illness course

d. relevant treatments

e. prognosis

f. psychophysiological components

g. methods for primary and secondary prevention

h. interpersonal and cultural context

\section{Clinical Assessment of Common Primary Care Conditions}

Objective: To acquire knowledge and expertise in the assessment of relevant cognitive, affective, behavioral, relational, social, and psychophysiological components for all common conditions seen in primary care, including

a. knowledge of common medical assessment methods and ability to move through a medical assessment process to case formulation using the biopsychosocial model

b. ability to detect subthreshold clinical problems (e.g., early signs of substance abuse)

c. knowledge of mental health problems, such as anxiety and depression, associated with certain medical illnesses

d. expertise in targeted, brief interviewing methods

e. knowledge of and expertise in the use of empirically supported psychometrics relevant to common primary care conditions, including

(1) awareness of limitations of traditional measures in primary care settings

(2) knowledge of normative data relevant to primary care

(3) knowledge and skills with brief screening instruments

f. expertise in triage

g. skills in obtaining information from collateral persons

h. skills in working under time-demand pressures

i. skills in starting with an undifferentiated clinical population and sorting through various domains of information quickly

j. skills in targeting the assessment to the referral question in language that is meaningful to the person who made the referral

k. ability to conduct assessments in medical settings, such as an exam room, the emergency department, or a hospital room

\section{Clinical Interventions in Primary Care}

Objective: To acquire knowledge and skill in implementing empirically supported interventions and awareness of other clinically supported interventions for the prevention and treatment of the most common conditions in primary care, including

a. skills in developing a psychological treatment plan to include collaborative care

b. skills in individual, couples and family, and group therapy

c. skills in supportive and cognitive-behavioral therapy, crisis intervention, family systems approaches, psychoeducation, and relapse prevention

d. skills in case management

e. skills in negotiating treatment plans that are mutually acceptable to the patient, family, and health care team

f. skills in increasing motivation for change and adherence

g. skills in implementing interventions through other providers

h. knowledge of community resources

i. skills in designing culturally sensitive interventions for local populations

j. practical, concrete problem-solving skills

k. knowledge of when to refer patients needing a more intense level of care (e.g., partial hospitalization, emergency care, hospitalization)

\section{Continues}




\section{Interprofessional Collaboration in Primary Care}

Objective: To acquire knowledge and skill in interprofessional primary health care, including

a. knowledge of other disciplines integrally involved in primary care (including but not limited to family practitioners, pediatricians, internists, obstetricians-gynecologists, nurse practitioners, registered nurses, licensed practical nurses, physician assistants, nutritionists, midwives, alternative healers, and social workers), with special attention to

(1) roles and functions

(2) education and training background

(3) scope of practice and boundary issues

(4) values and priorities

b. expertise in collaboration with other professions, including

(1) ability to discriminate individual differences from discipline differences

(2) skills in coordination of care across the lifespan

(3) skills in clear communication with other disciplines

(4) skills in cocreating an integrated treatment plan

c. expertise in consultation, such as

(1) patient-centered approaches

(2) consultee-focused strategies

(3) brief curbside methods

d. knowledge of medical specialties frequently consulted by primary care providers, especially skill in referral to and managing consultations with other providers

\section{Ethical Issues in Primary Care}

Objective: To be able to identify the distinctive ethical issues encountered in primary care practice, including but not limited to awareness of a. the multiple consumers of services and identification of potential role conflicts

b. problems encountered in team functioning (e.g., diffusion of responsibility) c. the psychologist's scope of practice

d. distinctive issues related to informed consent and confidentiality (e.g., documentation and negotiating with the patient to share relevant information with the primary care team)

e. the potential for dual relationships

f. management issues when involved with multiple family members across the life span

\section{Legal Issues in Primary Care}

Objective: To be able to identify the distinctive legal issues often encountered in primary care practice, including but not limited to

a. practice within scope of licensure

b. possibilities of shared liability

\section{Professional Issues in Primary Care}

Objective: To be aware of and skilled in the special professional issues found in primary care practice, including

a. differences between on-site and off-site collaborative practice

b. differences between working with one versus multiple groups of primary care providers

c. personality issues in collaborative practice

d. reimbursement issues in managed care, Medicaid, Medicare, and other insurances, including differences in coverage for medical and psychological care

e. the ability to address decisions regarding amount of nonreimbursed services to provide to referral sources (e.g., curbside consults, triage),

f. knowledge and skill in relevant marketing strategies

g. consideration of salaried versus fee-for-service models in primary care,

h. commitment to lifelong learning and skills in self-assessment of knowledge and competencies

i. the ability to function in different roles (team leader, direct service provider, consultant, case manager)

\section{Appendix B}

\section{Common Conditions Seen in Primary Care}

Abdominal pain
Adjustment disorders
Anxiety disorders
Arthritis
Asthma
Attention-deficit/hyperactivity
$\quad$ disorder
Back pain
Birth control
Chest pain
Chronic obstructive pulmonary
disease

Depression
Dermatitis
Developmental problems (toileting, sleep,
oppositional behavior, social
relationships, learning, puberty,
marriage, aging, death)
Diabetes
Domestic violence
Earache
Family issues (e.g., divorce, blended
families)
Fatigue

\author{
Pregnancy \\ Sedentary lifestyle \\ Sexual disorders \\ Sexual trauma (sexual abuse, rape) \\ Sleep disorders \\ Substance use and abuse \\ Somatoform disorders \\ Stress reactions \\ Tobacco use \\ Upper respiratory infections (sore \\ throat, cough) \\ Urinary problems (incontinence,
}

This list of conditions is based on Woodwell (1999, the National Ambulatory Care Medical Survey), Weiss (2000, 20 Common Problems in Primary Care), and Schroeder (1997a, common pediatric problems). 